\title{
A Comprehensive Environmental Life Cycle Assessment of the Use of Hydrochar Pellets in Combined Heat and Power Plants
}

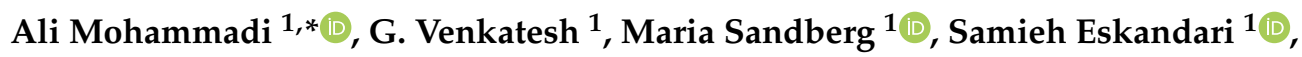 \\ Stephen Joseph ${ }^{2}$ and Karin Granström ${ }^{1}$ \\ 1 Department of Engineering and Chemical Sciences, Karlstad University, 65188 Karlstad, Sweden; \\ venkatesh.govindarajan@kau.se (G.V.); maria.sandberg@kau.se (M.S.); \\ samie.eskandari@gmail.com (S.E.); karin.granstrom@kau.se (K.G.) \\ 2 School of Materials Science and Engineering, University of New South Wales, \\ Sydney, NSW 2052, Australia; s.joseph@unsw.edu.au \\ * Correspondence: ali.mohammadi@kau.se; Tel.: +46-547-002-480
}

Received: 14 September 2020; Accepted: 28 October 2020; Published: 30 October 2020

\begin{abstract}
Hydrothermal carbonization (HTC) has been seen as a potentially beneficial process for converting wet biomass into value-added products. It is, however, necessary to overcome the challenges associated with handling the powdered form of hydrochar-a solid product of the HTC process-by controlling the formation of dust and facilitating smoother transportation and distribution in a potentially wide marketplace. In this paper, the authors investigate the environmental consequences of different alternatives for using hydrochar pellets produced from mixed sludges from pulp and paper mills in Sweden, using the environmental life cycle assessment (E-LCA). Two scenarios for possible end-uses of hydrochar in combined heat and power (CHP) plants as a source of energy (heat and electricity) were assessed. In these scenarios, hydrochar pellets were assumed to be combusted in CHP plants, thereby avoiding the use of combustible solid wastes (Scenario A) and coal (Scenario B), respectively, to recover energy in the form of electricity and heat. The environmental damages to Human Health, Ecosystem Quality, Climate Change, and Resources are evaluated based on 1 tonne of dry sludge as the functional unit. The results from this analysis illustrate that Scenario $B$, in which hydrochar replaces coal, offers the greatest reduction in all the environmental damage characterizations, except the Resources category. The displacement of energy-based coal due to hydrochar combustion contributed most significantly to the environmental damages wrought by the system-ranging from 52\% in Resources to 93\% in Ecosystem Quality. Overall, the results highlight that the application of hydrochar pellets for energy recovery to offset waste- and coal-based energy sources has great environmental benefits. The favorability of sludge hydrochar over solid wastes as fuel for CHP plants may be counter-intuitive at first, since HTC is an energy-intensive process, but when accounting for the necessity of dependence on imports of wastes for instance, the hydrochar pellet may well emerge as a good option for CHPs in Sweden.
\end{abstract}

Keywords: mixed sludges; hydrochar pellets; environmental damages; E-LCA; resources

\section{Introduction}

Incineration plants for energy recovery may have the supply of heat as their sole reason for existence, in which case, they are referred to as heat-only boilers. At the other end of the spectrum of energy supply, there are power plants supplying only electricity. Any waste heat that is generated may at best find use within the plant, but is not sold to external end-users. These are what are referred to, in thermodynamic parlance, as condensing power plants. In between these two extremes lie the 
combined heat and power (CHP) plants [1]. Usually, the primary purpose of a CHP may be the provision of district heating services, making heat energy its main output. This will imply that the electricity generated first within a CHP is actually a "by-product", which incidentally has a higher exergy content and thereby, a higher specific economic value [1]. The input mix to CHPs can be quite varied-fossil fuels (including peat), biofuels, and solid wastes. The solid wastes can be biotic (of biological origin, or organic in nature, and therefore, renewable) or plastics sourced from petroleum (essentially biotic but renewable only over several human lifetimes). It would be a truism to state that the demand of the century is a drastic reduction in the dependence on fossil fuels, to mitigate global warming and climate change effects, and a smooth transition to a so-called circular bioeconomy where biofuels and biowastes are highly preferred to coal [2].

Solid wastes with fuel value generated in the technosphere (households and industries) are comprised largely of paper and plastics. Now, if one strictly adheres to the recommended waste management hierarchy- "Reduce", "Reuse", and "Recycle"- they are the preferred options. Energy recovery follows in fourth position, and is, while being inferior to the first three, certainly preferable to landfilling, in which all value (material and energy) is lost subterra (usually for good; at times, temporarily when urban mining remains an option for the future). While many European countries still use fossil fuels in their CHPs, Sweden has gone a notch or two higher by discontinuing coal and also importing wastes from countries like Norway [3] and the UK. Persson and Münster [4] have, however, labelled continental exports and imports of wastes as being "untenable" - the authors imply that when viewed from a long-term perspective, this practice must cease. When faced with this two-pronged challenge- - phasing out of fossil fuels from fuel mixes adopted by Swedish CHPs on the one hand, and the discontinuation of continental imports of solid wastes as fuels on the other-and yet, having to meet the target of generating electricity by $100 \%$ renewable sources by 2040 [5], Swedish CHPs are faced with a Hobson's choice-resorting to locally sourced, climate-neutral substitutes.

Local sourcing of raw materials is by itself a strong imperative for sustainable development, while the transition towards a perfectly circular economy can be aided and speeded up if these locally sourced substitute/s could be found in wastes (or rather, "side-streams" in industrial ecology parlance) from Swedish industries. Sweden is known for its pulp and paper sector, and the outflows of sludge from this sector can be tapped for the recovery of several value-added products-among them, hydrochar (biochar produced through the hydrothermal carbonization-HTC route), which could start figuring in pellet form in the fuel mixes of CHPs. Over time, hydrochar could very well replace fossil fuels such as coal and solid wastes in Sweden and other countries in Europe. However, as observed by [6], the inherent properties of biochar such as high dust levels and low bulk density together with a wide range of physical shapes/sizes create big challenges for their handling logistics and combustion technology. Pelletization confers improved fuel quality such as increased bulk density, durability, mechanical strength, and uniform shape and size, on biochar [7]. While the increased bulk density and mechanical strength reduce the storage and transportation costs, the dimensional uniformity serves to ease the handling and feeding of the same, while making them amenable to many industrial applications [8,9]. As Ahlroth et al. [10] and Zhu et al. [11] have observed, an additional benefit is that the potential heating value of the solid product (hydrochar) can also be enhanced hereby, vis-à-vis the corresponding raw biomass.

When different alternatives are available for the design of processes to obtain desired outputs, the most optimum one is decided on the basis of a multicriteria analysis-environmental, political, infrastructural, and economic. In this paper, the authors restrict themselves to one of these- the environmental. The tool of choice is (partial) environmental life cycle assessment (E-LCA). This, as readers know, within the framework of the ISO standards [12-14], enables analysts to look for possibilities to reduce the environmental impacts of products at different stages in their life cycles, conveying information to decision-makers in industry, government, and NGOs, which will assist in strategic planning, identifying relevant environmental performance indicators, marketing and 
promoting products and alternative processes, and educating in general. The E-LCA approach has been numerously applied on waste management systems [15-17].

Although there are several studies suggesting that hydrothermal carbonization (HTC) is an environmentally beneficial process, a systems-level evaluation of the environmental impacts associated with HTC and subsequent hydrochar combustion has not been well-documented in the scientific literature. The environmental footprint of the HTC of food wastes followed by the combustion of the hydrochar product in powder form, for energy production, was determined by Berge et al. [18] by adopting the E-LCA approach. In another work [19], the energy use impact and associated climate change effects of producing hydrochar briquettes co-formed with coal fines for use as a fuel in power plants has been investigated using E-LCA as the tool. In said study, the source of the hydrochar was loblolly pine and the process adopted was fast HTC.

For soil application of hydrochar, Mohammadi et al. [20] studied the environmental implications of the production of hydrochar from pulp and paper mill biosludge for application in forest ecosystems. A detailed system analysis is imperative when one wishes to more objectively identify and quantify environmental costs and benefits in the entire life cycle of a product. Considering that using HTC in this manner is in its infancy, a major obstacle associated with conducting such a comprehensive analysis of HTC is the lack of relevant data.

In this paper, the use of E-LCA to comparatively analyze the environmental impacts and damage consequences associated with the utilization of hydrochar pellets in CHPs as a source of energy for heat and electricity generation, has enabled the authors to contribute to some of the said purposes of the tool referred to above. Hydrochar pellets are produced from pulp and paper mill sludge and are assumed to substitute coal and solid wastes in CHPs. This study is part of the continuum to earlier ones by the authors, in which alternate approaches to handling mixed sludges from pulp and paper mills were studied and analyzed for their environmental footprints.

\section{Materials and Methods}

\subsection{Goal and Scope Definition}

The aim of this E-LCA is to quantify the environmental impacts (and damage) of the HTC of pulp and paper mill sludge and the subsequent combustion of the hydrochar product for energy production in CHP plants, replacing two different fuels (coal and solid wastes). The mixed sludge was assumed to be composed of fiber sludge and biosludge in equal proportion. This study also attempts to identify the most impactful processes and understand how parameters related to sludge waste carbonization followed by hydrochar combustion affect the environmental consequences of two alternative systems. The selected fuels in this assessment are commonly used in European CHP plants.

The mass-based functional unit (FU) is commonly adopted in E-LCA analyses of waste treatment systems $[15,21,22]$. In the current study, 1 tonne $(t)$ of dry matter sludge in each CHP scenario has been chosen as the FU.

\subsection{System Boundaries and Scenarios}

The system includes all processes starting from sludge gathering right up to the end-use/s of the hydrochar pellets and the incinerated ash (the by-product generated), with all the conversion/transformation processes in between these two (Figure 1). In other words, the assessment encompasses the "cradle" (the collection of the sludge) to the end-uses, which may be labelled as "graves" or "cradles" depending on the perspective adopted. The two scenarios which were considered in the analysis have been described hereunder in detail. Sludge incineration without energy recovery was taken into account as the conventional mode of handling against which the two pellet scenarios were compared.

Scenario A, where hydrochar pellets substitute solid waste, investigates the impacts of hydrochar production using mixed sludges from pulp and paper mills, in an HTC reactor, and using the resulting 
solid fuel in a heat- and electricity-producing power unit. The collected sludge is dewatered and then, transported to the HTC plant where it is converted into hydrochar and gas (Figure 1). The hydrochar is pelletized and delivered to the CHP units to be combusted and to offset solid waste-based energy sources (electricity and heat) by avoiding the solid waste combustion process. The exhaust gases, owing to their high carbon dioxide content, are not captured for combustion. Scenario B, in which hydrochar pellets substitute coal, also uses mixed sludges from pulp and paper mills to generate hydrochar via the HTC process (Figure 1). The exhaust gases are assumed to be released to the atmosphere. After pelletizing hydrochar, it is then transported to CHP plants to replace coal in heat and electricity production.

In both the scenarios, the process water including solid residues (organic compounds) is treated in a wastewater treatment (WWT) process, where the solid residues are separated from the liquid part and returned to the HTC reactor, and added to the incoming feedstock of the next cycle of the process. The cleaned water from WWT process is then discharged to the hydrosphere. The residual bottom ash from the hydrochar combustion from both the CHP units is delivered to landfill sites. To evaluate the environmental footprint of co-products, the system expansion approach was adopted in this work.

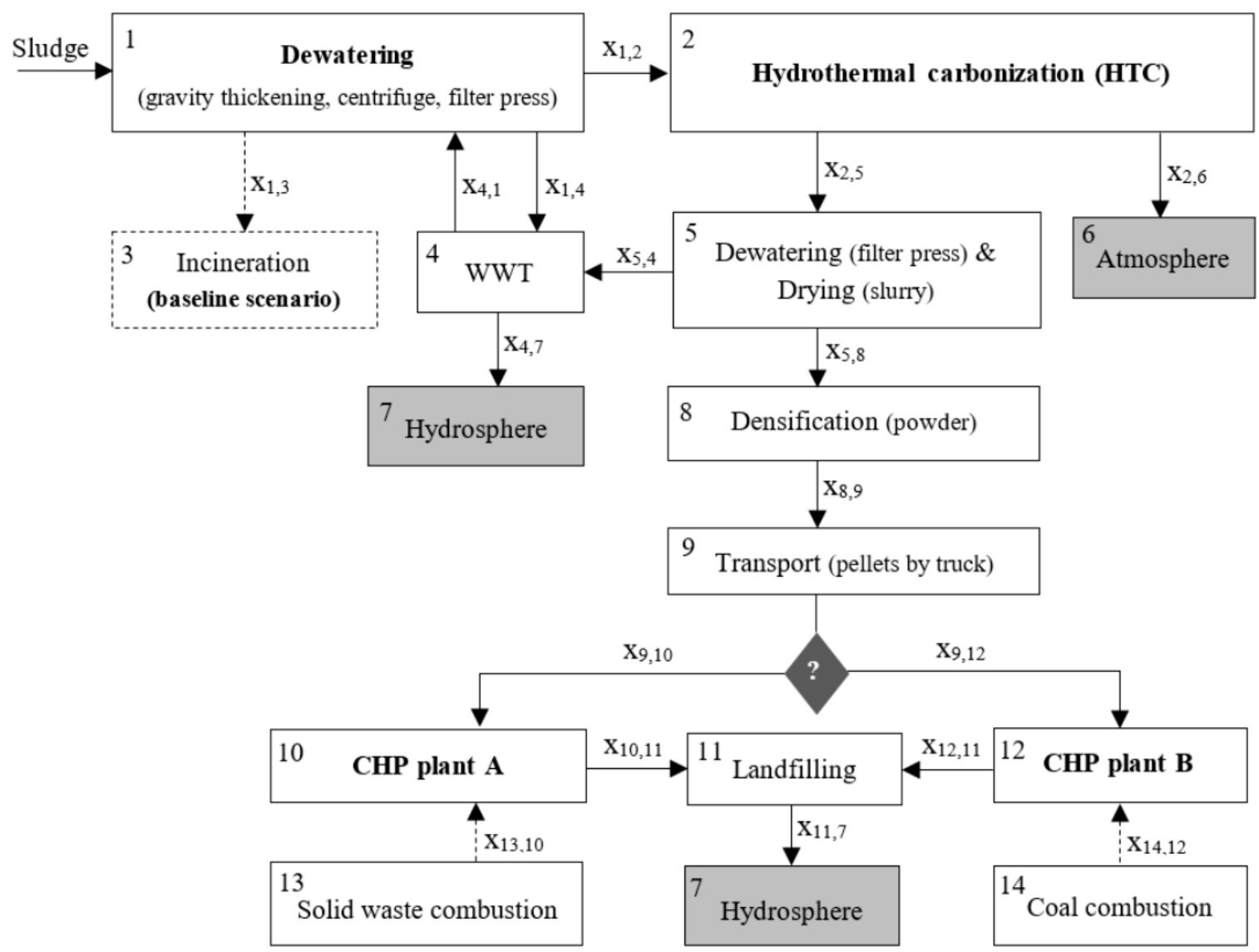

Figure 1. Life cycle diagrams for using HC pellet in CHP plants. The dashed lines represent avoided processes (the acronyms $\mathrm{HC}, \mathrm{WWT}$, and CHP represent hydrochar, wastewater treatment, and combined heat and power, respectively). The boxes shaded in grey represent the environmental sinks. The labelled flows are: $X_{1,2}$ and $X_{1,3}$-dewatered sludge; $X_{1,4}$ and $X_{5,4}$-process water; $X_{4,1}$-solid residues; $X_{2,5}$-slurry HC; $X_{4,7}$-treated water; $X_{2,6}$-gases; $X_{5,8}-H C$ powder; $X_{8,9}, X_{9,10}$, and $X_{9,12}$-HC pellet; $X_{10,11}$ and $X_{11,12}$-ash; $X_{11,7}$ - heavy metals; $X_{13,10}$ - solid waste; $X_{14,12}$ - coal.

\subsection{Inventory Analysis}

The life cycle inventory included data from the relevant literature, HTC process experiments, and the ecoinvent 3.1 [23] and ELCD databases [24] under Swedish conditions for all the scenarios. Inventory data for the HTC process were gathered from hydrochar experiments carried out by Ahlroth, 
Bialik, and Jensen [10] and Fuglesang et al. [25] in Sweden. The experiment evaluated the HTC treatment of two different types of sludge from the pulp and paper industry in Innventia's Parr reactor [26] at $200{ }^{\circ} \mathrm{C}$, for $3 \mathrm{~h}$ with a hydrochar yield of $68.5 \%$ and $60 \mathrm{~kg}$ exhaust gas, which is released to the air. The exhaust gas is composed of $\mathrm{CO}_{2}$ (over 90\%) [27], and thereby not combustible. In the experiments, fiber sludge and biosludge were considered, and the average data (elemental and energy analyses) of these two sludges and their corresponding hydrochars were used in the current study. The slurry hydrochar from the HTC stage was dewatered using a filter press and dried to a moisture content of $8 \%$. The latent energy required to evaporate the moisture away was calculated using its enthalpy of vaporization (2.5 MJ per kg of water). The total thermal energy needed for material drying was calculated assuming an energy loss factor of $25 \%$ [28]. However, this energy requirement was met by the extra (waste) heat available in pulp and paper mills, thanks to the incineration of organic waste materials such as wood residues.

The produced hydrochar was then assumed to be pelletized by a medium-size pelletizing machine with a product mass flow of around $40 \mathrm{~kg}$ per h and electricity requirement of approximately $0.05 \mathrm{kWh}$ per kg pelleted hydrochar [29]. The densification process for hydrochar was modeled considering a material loss factor of $10 \%$ based on the experiments conducted at Karlstad University (data not shown). The electricity required for the dewatering, HTC, and densification processes was sourced from the Swedish electricity grid.

The next stage of this process is hydrochar pellet combustion for heat and power generation. Because of a lack of data associated with the energy required for hydrochar combustion, and the distribution of heavy metal elements during this process, hydrochar combustion is assumed to behave in the same way as sludge incineration does; thus, the incineration module of mixed sludges [30] was employed for both scenarios A and B to model hydrochar combustion in CHP plants including emissions and the flue gas treatment process. Electricity and heat produced from the hydrochar combustion were calculated based on the energy recovery efficiencies reported in [31], where HTC was used to treat olive mill wastes and was followed by combustion for energy recovery. The in-plant electricity use in the CHP is $4.5 \%$ of the generated output. A $10 \%$ heat loss in the district heating network was considered based on a transmission distance of $5 \mathrm{~km}$. The use of heat from CHP and HTC processes was assumed to avoid the use of district heating fuels in both scenarios. The gaseous emissions associated with the incineration [32] and HTC facilities [33] were taken into account based on the published experimental studies.

Much uncertainty still exists about the effects of HTC and combustion on heavy metals in the sludge as well as the partial solubilization of the ash-forming components during the HTC process. Therefore, it is difficult to model and requires consideration of many factors such as reaction time and temperature, process water $\mathrm{pH}$, and characteristics of the sludge. However, some experimental works $[25,34]$ reported that heavy metals mostly remain in the solid residues produced during the thermochemical treatment process. In this assessment, we assumed that all the heavy metals are removed with the solid residues and hydrochar on the one hand, and the ash generated on the other, during the HTC and combustion processes, respectively. Likewise, the ash-forming components were considered to remain integrated within the hydrochar. We estimated the leachability of heavy metals in the ash, which is landfilled according to Latosińska and Gawdzik [35]. We assumed that the construction and maintenance of the infrastructure are depreciated over a long lifetime; hence, these were not included in the E-LCA. The assumptions and life cycle inventory for both the scenarios are illustrated in Table 1. 
Table 1. Inventory for application of hydrochar pellets in CHP plants (expressed per tonne of dry sludge).

\begin{tabular}{|c|c|c|c|}
\hline & Unit & Amount & Comments/Source \\
\hline \multicolumn{4}{|l|}{ Inputs } \\
\hline Electricity & $\mathrm{kWh}$ & 577 & \multirow{3}{*}{ To $65 \% \mathrm{MC}$} \\
\hline Dewatering sludge & $\mathrm{kWh}$ & 115 & \\
\hline HTC process & $\mathrm{kWh}$ & 120 & \\
\hline Dewatering slurry $\mathrm{HC}$ & kWh & 13 & \multirow{2}{*}{ From $50 \%$ to $20 \% \mathrm{MC}$} \\
\hline Wastewater treatment & $\mathrm{kWh}$ & 296 & \\
\hline Pelletizing hydrochar & $\mathrm{kWh}$ & 33 & \multirow{2}{*}{$\begin{array}{c}{[29]} \\
\text { From } 20 \% \text { to } 8 \% \mathrm{MC}\end{array}$} \\
\hline Heat for drying HC & MJ & 94 & \\
\hline Heat for HTC process & GJ & 4.32 & \multirow[b]{2}{*}{ Mixture of fiber sludge and biosludge } \\
\hline Mixed sludges & $\mathrm{kg}$ & 1000 & \\
\hline \multicolumn{4}{|l|}{ Outputs } \\
\hline Gas & $\mathrm{kg}$ & 60 & \multirow{2}{*}{$\begin{array}{c}\text { Experimental results described in }[10,25] \\
10 \%, 3 \% \text { and } 1 \% \text { losses during pelletizing, } \\
\text { handling, and transport }\end{array}$} \\
\hline Hydrochar & $\mathrm{kg}$ & 623 & \\
\hline \multicolumn{4}{|l|}{ Emissions from hydrochar production } \\
\hline $\mathrm{CH}_{4}$ & $\mathrm{~g}$ & 231 & [33] \\
\hline $\mathrm{CO}$ & $\mathrm{g}$ & 474 & [33] \\
\hline $\mathrm{H}_{2}$ & g & 0.92 & [33] \\
\hline \multicolumn{4}{|l|}{$\begin{array}{l}\text { Energy substitution through use of } \mathrm{HC} \\
\text { pellets in CHP plants }\end{array}$} \\
\hline Heat & GJ & 2.96 & \\
\hline Electricity & kWh & 529 & \\
\hline \multicolumn{4}{|l|}{ Emissions to water from landfilling of ash } \\
\hline Cadmium (Cd) & $\mathrm{g}$ & 1.65 & [35] \\
\hline Chromium (Cr) & $\begin{array}{l}0 \\
g\end{array}$ & 0.0 & {$[35]$} \\
\hline Copper (CU) & $\mathrm{g}$ & 2.89 & [35] \\
\hline Nickel (Ni) & $\mathrm{g}$ & 0.94 & [35] \\
\hline Lead $(\mathrm{Pb})$ & $\mathrm{g}$ & 0.94 & [35] \\
\hline Zinc (Zn) & $\mathrm{g}$ & 149.46 & [35] \\
\hline \multicolumn{4}{|l|}{ Other assumptions } \\
\hline Hydrochar yield & $\%$ & 68.5 & Experimental results described in $[10,25]$ \\
\hline Transport distance & $\mathrm{km}$ & 200 & From HTC unit to CHP plant \\
\hline Net calorific value & $\mathrm{MJ} / \mathrm{kg}$ & 20.9 & On dry basis $[10,25]$ \\
\hline Ash content of hydrochar & $\%$ & 15.5 & On dry basis $[10,25]$ \\
\hline Combustion efficiency & $\%$ & 90.1 & [36] \\
\hline Electricity conversion efficiency & $\%$ & 17 & [31] \\
\hline Heat conversion efficiency & $\%$ & 56 & {$[31]$} \\
\hline Efficiency for transferring heat & $\%$ & 95 & $\begin{array}{c}\text { From combusted gases to heating } \\
\text { applications on-site }\end{array}$ \\
\hline
\end{tabular}

\subsection{Impact Assessment}

SimaPro 8.0.4 [37] with its Ecoinvent libraries [23] and the Impact 2002+ method [38] were used to perform the midpoint and endpoint life cycle impact assessments. According to the ISO 14,042 guidelines, LCIA can be performed by the following four steps:

(1) Selection of impact categories and classification. (2) Characterization. (3) Normalization. (4) Weighting.

Of the aforenamed four steps, the first two are mandatory, while the last two are optional. In this analysis though, all the four steps have been adopted. Inventory flows are characterized and grouped into 15 impact categories: carcinogens (CA), non-carcinogens (NCA), respiratory inorganics (RI), ionizing radiation (IR), ozone layer depletion potential (ODP), respiratory organics (RO), aquatic ecotoxicity (AET), terrestrial ecotoxicity (TE), terrestrial acidification/nutrification (TA/N), land occupation (LO), aquatic acidification (AA), aquatic eutrophication (AE), global warming (GWP), 
non-renewable energy (NRE) use, and mineral extraction (ME). These impacts are subsequently further characterized (second-level) and grouped into four damage categories: human health (HH) in Damage Adjusted Years of Life (DALY), ecosystem quality (EQ) in Potentially Disappeared Fraction (PDF $\mathrm{m}^{2} \mathrm{yr}$ ), climate change (CC) in $\mathrm{kg} \mathrm{CO}_{2}$ eq., and resources (RE) in MJ primarily [38]. Figure 2 shows the damage categories and their corresponding impacts. Default normalization factors (refer to Table 2) are used, and equi-weighting is adopted to express the final result as a single score [38].

\begin{tabular}{|c|c|}
\hline Carcinogens (CA) & \\
\hline \multicolumn{2}{|l|}{ Non-Carcinogens (NCA) } \\
\hline \multicolumn{2}{|l|}{ Ionizing radiation (IR) } \\
\hline \multicolumn{2}{|l|}{ Respiratory inorganics (RI) } \\
\hline \multicolumn{2}{|l|}{ Respiratory organics (RO) } \\
\hline \multicolumn{2}{|l|}{ Ozone layer depletion (ODP) } \\
\hline \multicolumn{2}{|l|}{ Aquatic ecotoxicity (AET) } \\
\hline \multicolumn{2}{|l|}{ Terrestrial ecotoxicity (TE) } \\
\hline \multicolumn{2}{|l|}{ Terrestrial acid/nutrif (TA/N) } \\
\hline \multicolumn{2}{|l|}{ Land occupation (LO) } \\
\hline \multicolumn{2}{|l|}{ Aquatic acidification (AA) } \\
\hline \multicolumn{2}{|l|}{ Aquatic Eutrophication (AE) } \\
\hline \multicolumn{2}{|l|}{ Global warming (GWP) } \\
\hline \multicolumn{2}{|l|}{ Non-renewable energy (NRE) } \\
\hline \multicolumn{2}{|l|}{ Mineral extraction (ME) } \\
\hline Impact categories & Damage categories \\
\hline
\end{tabular}

Figure 2. Damage categories and the related midpoint impact categories based on Impact 2002+ method.

Table 2. Normalization factors for the four damage categories for Western Europe [38].

\begin{tabular}{ccc}
\hline Damage Categories & Normalization Factors & Unit \\
\hline Human health (HH) & 0.0077 & DALY/pers/yr \\
Ecosystem quality (EQ) & 4650 & $\mathrm{PDF}^{2}$.yr/pers/yr \\
Climate change (CC) & 9950 & $\mathrm{~kg} \mathrm{CO}_{2} / \mathrm{pers} / \mathrm{yr}$ \\
Resources (RE) & 152,000 & $\mathrm{MJ} / \mathrm{pers} / \mathrm{yr}$ \\
\hline
\end{tabular}

\section{Results and Discussion}

\subsection{Environmental Performance of Two Scenarios}

The E-LCA results of the environmental impacts (midpoint values) and the environmental damages (endpoint values) for the two hydrochar pellet pathways are presented in Tables 3 and 4, respectively.

A positive impact/damage potential shows a burden to the environment (negative environmental effects), while a negative potential shows a reduction in environmental impacts (positive environmental effects). For both the scenarios, emission abatement was greater than the emissions per se, resulting in a negative value for most of the environmental impacts. However, the results indicate that some impacts such as CA, AE, and TE have a greater cost to environment in Scenario A, while other impacts like NCA, IR, and ODP were greater in Scenario B. In terms of damage categories, Scenario B, in which hydrochar pellets replace coal in CHP plants, offered better environmental performance in all the 
categories except resources compared to Scenario A, in which hydrochar pellets substitute solid waste and result in saving the raw materials, e.g., aluminum, copper, iron, and nickel, embedded in municipal and industrial waste. Figure 3 presents the comparison between the two cases: differences are large, varying from $10 \%$ for resources to $83 \%$ for climate change. This high difference in climate change is because the avoided process of coal combustion in Scenario B significantly emits more GHGs, vis-à-vis the avoided process of solid waste combustion in Scenario A.

The two hydrochar systems, where hydrochar pellets substitute solid waste (Scenario A) and coal (Scenario B) in CHP plants, considerably improved the environmental consequences of management of sludge relative to the baseline scenario (i.e., incineration of sludge) with respect to the different impacts and their corresponding damages. However, the environmental performance of the application of hydrochar from sludge for energy purposes is influenced by its usage in CHP plants running with different fuels. The observed differences between the hydrochar scenarios are mostly due to the avoidance of environmental impacts thanks to the displacement of the use of solid wastes and coal as fuels. The avoidance of environmental impacts is thus credited to each system.

Similar impact-mitigation results of hydrochar systems were found in other studies [18,31], where the HTC of food wastes and the subsequent combustion of the generated hydrochar for energy production were evaluated via the E-LCA method. In the case of hydrochar production from pulp and paper mill sludge for use in CHP plants, no studies have been published. However, the potential of hydrochar pellets from sludge for use as fuels has been reported by a few researchers $[36,39]$.

Table 3. Midpoint values for impact categories. Scenario A: Hydrochar pellets to substitute solid waste; Scenario B: Hydrochar pellets to substitute coal.

\begin{tabular}{|c|c|c|c|c|}
\hline Impact category & Abbreviation & Units & Scenario A & Scenario B \\
\hline Carcinogens & $\mathrm{CA}$ & $\mathrm{kg} \mathrm{C}_{2} \mathrm{H}_{3} \mathrm{Cl}$ eq. & -0.0137 & -0.00479 \\
\hline Non-Carcinogens & NCA & $\mathrm{kg} \mathrm{C}_{2} \mathrm{H}_{3} \mathrm{Cl}$ eq. & -0.0138 & -0.00105 \\
\hline Respiratory inorganics & RI & $\mathrm{kg} \mathrm{PM}_{2.5}$ eq. & -0.000366 & -0.00054 \\
\hline Ionizing radiation & IR & kg C-14 eq. & -9.09 & 10.3 \\
\hline Ozone layer depletion & ODP & kg CFC-11 eq. & $-3.0 \times 10^{-7}$ & $9.79 \times 10^{-8}$ \\
\hline Respiratory organics & $\mathrm{RO}$ & $\mathrm{kg} \mathrm{C}_{2} \mathrm{H}_{4}$ eq. & -0.000224 & -0.000256 \\
\hline Aquatic ecotoxicity & AET & kg TEG water & 105 & 56.2 \\
\hline Terrestrial ecotoxicity & $\mathrm{TE}$ & kg TEG soil & -13.2 & -32.6 \\
\hline Terrestrial acid/nutrif & $\mathrm{TA} / \mathrm{N}$ & $\mathrm{kg} \mathrm{SO} \mathrm{S}_{2}$ eq. & -0.00606 & -0.00611 \\
\hline Land occupation & LO & $\mathrm{m}^{2}$ org.arable & -0.0281 & -0.01 \\
\hline Aquatic acidification & AA & $\mathrm{kg} \mathrm{SO}_{2}$ eq. & -0.00228 & -0.00345 \\
\hline Aquatic eutrophication & $\mathrm{AE}$ & $\mathrm{kg} \mathrm{PO}_{4} \mathrm{P}$-lim & -0.000165 & -0.000115 \\
\hline Global warming & GWP & $\mathrm{kg} \mathrm{CO} 2$ eq. & -0.121 & -0.723 \\
\hline Non-renewable energy use & NRE & MJ primary & -2.35 & -2.23 \\
\hline Mineral extraction & ME & MJ surplus & -0.125 & -0.00245 \\
\hline
\end{tabular}

Table 4. Endpoint values for damage categories.

\begin{tabular}{ccccc}
\hline Damage Category & Abbreviation & Units & Scenario A & Scenario B \\
\hline Human health & $\mathrm{HH}$ & $\mathrm{DALY}$ & $-3.36 \times 10^{-7}$ & $-3.92 \times 10^{-7}$ \\
Ecosystem quality & $\mathrm{EQ}$ & $\mathrm{PDF}-\mathrm{m}^{2} \cdot \mathrm{yr}$ & -0.136 & -0.272 \\
Climate change $^{\mathrm{a}}$ & $\mathrm{CC}$ & $\mathrm{kg} \mathrm{CO}_{2}$ eq. & -0.121 & -0.723 \\
Resources & $\mathrm{RS}$ & $\mathrm{MJ} \mathrm{primary}$ & -2.48 & -2.23 \\
\hline
\end{tabular}

a In climate change damage category, only one impact "GWP" exists, and the factor for converting GWP impact to the CC damage category is 1, based on the method adopted, and this leads to the same figures and units at midpoint and endpoint levels. 


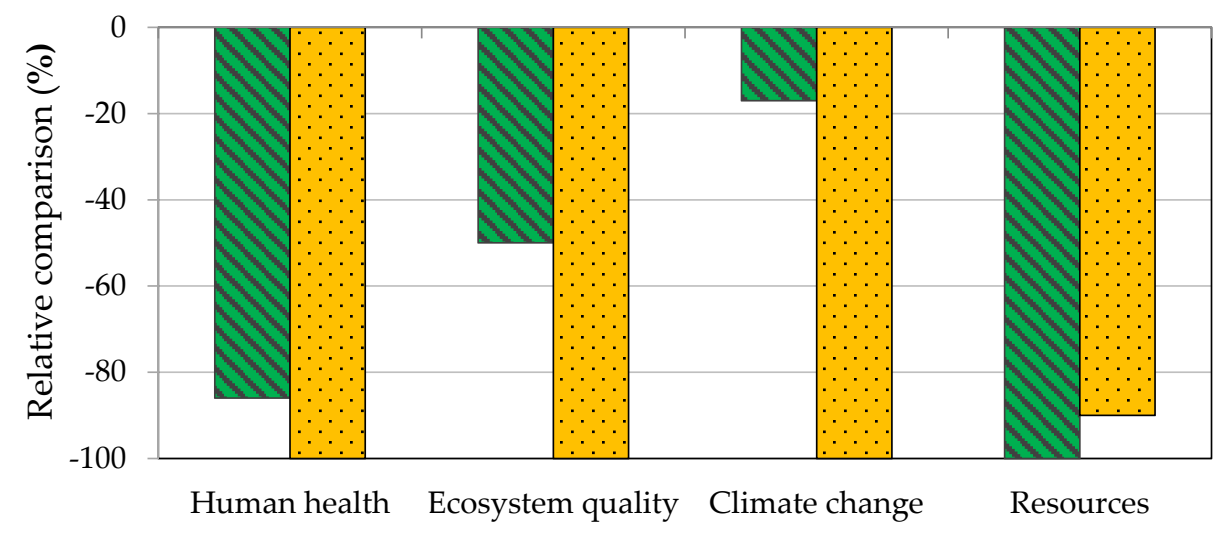

Damage categories

\begin{tabular}{|l|}
\hline Scenario A \\
\hline Scenario B \\
\hline
\end{tabular}

Figure 3. Environmental damage characterization of hydrochar scenarios: relative comparison between the two alternative hydrochar pellet applications.

\subsection{Contribution Analysis}

Results from the contribution analysis are presented in Figure 4. This figure illustrates the contributions (in percentage) of the different processes, including sludge dewatering, hydrochar combustion, densification of produced hydrochar, and landfilling of incinerated ash. The percentage contribution of each of these processes is according to its individual contribution to the corresponding damage potential. It is seen that the avoided use of conventional (currently used) fuels (solid waste and coal) was the dominant process in all the environmental damages in both scenarios. The contribution of this process (energy displaced in Figure 4) ranged from 52\% in improvement of RE to 95\% reduction in EQ damage in Scenario B. These results are in agreement with the findings from Eriksson et al. [40]. Berge, Li, Flora, and Ro [18] reported that hydrochar combustion contributed most significantly to the overall environmental impacts of the system, with most of the impacts-GWP, TA, and TE especially — being attributed to hydrochar combustion. This, courtesy of the substitution of lignite-sourced electricity in the wider system, contributed to over $90 \%$ of the offsets. Benavente, Fullana, and Berge [31] have also shown that GWP, TA, TE, ME, and human toxicity, benefited immensely thanks to such a substitution.

In our analysis, the production and densification of sludge hydrochar also contribute significantly to the environmental damage-to RE (about 22\%) and CC (27\% in Scenario A and 13\% in Scenario B). This is mainly due to the electricity required to run the HTC process and operate the pelletizing equipment. Sludge dewatering and wastewater treatment contributed $20 \%$ to $\mathrm{RE}$, owing to the electricity-intensiveness of these two processes. However, the impacts associated with sludge dewatering played a relatively smaller role in the $\mathrm{HH}(5 \%)$, EQ $(2 \%)$, and CC ( $11 \%$ and $5 \%$ in scenarios $A$ and $B)$ environmental damage characterization values. It must be mentioned at this juncture that the environmental impacts/damages due to the HTC process may change when it is scaled up, because of the changes in requirements for auxiliary equipment, which will be called for.

The avoided sludge incineration contributed slightly to reductions in $\mathrm{HH}, \mathrm{EQ}, \mathrm{CC}$, and RS damages by $3 \%, 1 \%, 2 \%$, and $5 \%$, respectively. Landfilling of the incinerated ash is responsible for around $7 \%$ of $\mathrm{HH}$ and $4 \%$ of EQ damages. This is largely due to the mobility of heavy metals in ash. For both the scenarios, transportation had a minor contribution, about $1 \%$, to all the damages. 


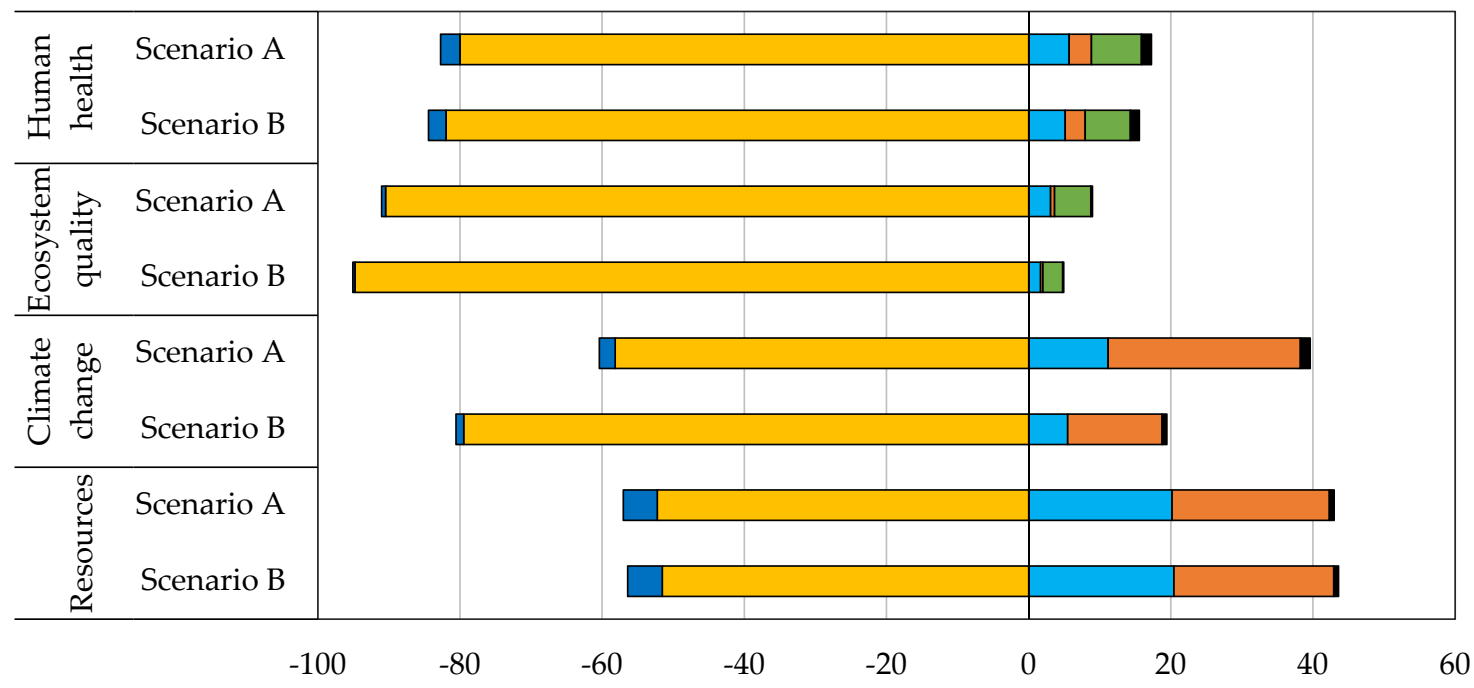

Contribution of life cycle stages (\%)

\begin{tabular}{|ll|}
\hline$\square$ DW \& WWT & $\square$ HC production \& Densification \\
$\square$ Energy displaced (CHP) & $\square$ Avoided sludge incineration \\
$\square$ Landfilling of ash & $\square$ Transport \\
\hline
\end{tabular}

Figure 4. Contribution of life cycle stages to Human Health, Ecosystem Quality, Climate Change, and Resources of management of $1 \mathrm{t}$ of dry sludge in scenarios A and B (the DW, WWT, HC, HTC, and CHP represent the dewatering, wastewater treatment, hydrochar, hydrothermal carbonization, and combined heat and power, respectively).

\subsection{Single-Score Analysis}

For an effective interpretation of the results from the comparative analysis, impact categories were normalized, weighted, and converted to a single score. Figure 5 shows the single score results based on one tonne of dry sludge. According to the results, both the systems analyzed in this study are environmentally preferable to the baseline scenario of combustion of mixed sludges. However, Scenario B, in which the sludge is converted to hydrochar pellets to replace coal, has a lower environmental footprint than Scenario A. This discrepancy could be attributed to the better performance of Scenario B in most of the damage categories relative to Scenario A, in which hydrochar pellets from sludge substitute solid waste in CHP units. Therefore, when hydrochar is used as biofuel, the environmental impacts are very much sensitive to the type of fuel replaced by the hydrochar and also the existing waste management system that the HTC process substitutes. [19,41].

Scenario A has better results only in the resources damage category, due to the greater reduction in NRE use and mainly ME impact because of avoiding the incineration of raw materials embedded in solid waste. Therefore, if the reduction in the use of non-renewable fuel sources and minerals is the main motivation, the use of hydrochar pellets to replace solid waste can be the preferred alternative for handling mixed sludges. However, the application of sludge hydrochar instead of coal is suggested if a comprehensive outlook and optimizing environmental and health costs are focused on. 


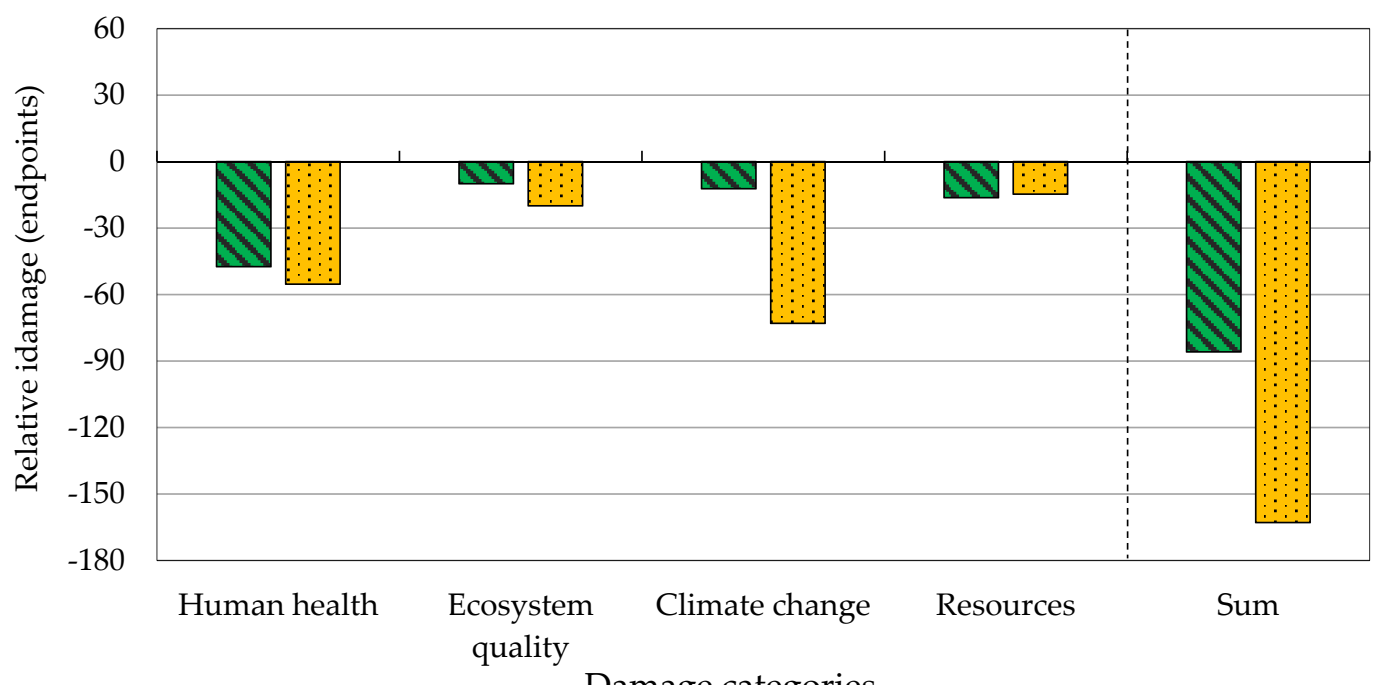

Damage categories

$\Delta$ Scenario A $\quad$ Scenario B

Figure 5. Normalized and weighted environmental and health damages (endpoints) for the hydrochar pellet systems. Scenario A: Hydrochar pellets to substitute solid waste; Scenario B: Hydrochar pellets to substitute coal.

\subsection{Implementation of Hydrochar Pellet Systems}

Coal accounts for a very small share in the Swedish power sector, but it dominates the power mixes in many other countries. Substituting it with hydrochar will be one of the many strategies which could be adopted to decarbonize the global energy sector. Sweden plans to achieve $100 \%$ renewable electricity generation by 2040, followed by zero net GHG emissions in 2045 [5]. Biomass is one of the most important fuels in Swedish district heat and electricity generation with about $46 \%$ [42] and 9\% [5] contributions, respectively. Therefore, the improvement of energy recovery from biomass sources is expected to play a key role in the attainment of Sweden's energy-related targets. Hence, it is beneficial to explore efficient ways to upgrade pulp and paper mill sludge into high value-added bioenergy. This raises the question - which form of biomass delivers the greatest energy benefits? Previous studies have indicated that the fuel quality of raw biomass can significantly be increased by the carbonization process and the resultant hydrochar has the potential to be used as a source of energy in firing units to replace conventional coal or other sources partially and reduce the environmental impacts [18,43]. By pelletizing hydrochars, fuel quality can be improved [11], and in addition to a decrease in the generation of nuisance dust, benefits related to transport, storage, and combustion are achieved. Liu, Quek, and Balasubramanian [6] concluded that the enhanced mechanical durability and considerably improved combustion characteristics make hydrochar pellets more suitable as solid fuels vis-à-vis raw biomass pellets. Therefore, carbonization of sludge feedstock, combined with pelletization, has the potential to obtain high-quality biomass fuel and to provide a better alternative for the utilization of raw sludge as a source of energy.

Our results showed that hydrochar also has the potential to replace solid waste in CHP units and deliver significant environmental benefits. The favorability of hydrochar pellets over solid wastes as a fuel for CHP plants may be counter-intuitive at first, due to the energy-demanding processes of HTC and pelletizing, but when accounting for the necessity of dependence on imports of wastes for instance, one moves towards substantiating the claim that sludge hydrochar may well emerge as a good option for CHPs in Sweden. It can be also seen from the literature that energy generation from solid wastes causes considerable environmental impacts-natural resources, global warming, and toxic emissions [17]. Eriksson, Finnveden, Ekvall, and Björklund [40] reported that waste incineration is usually the preferred option when incineration replaces landfilling. However, it cannot be denied that 
incineration is still an inferior option compared to material recovery, when viewed from a life cycle perspective. Hence, it is imperative that the potential for material recovery needs to be considered in future research in this field.

In addition to energy-related applications, hydrochar production from pulp and paper mill sludge and its use as a soil amendment can be a good option for waste-stream management strategies. Hydrochar pellets have been shown as a possible partial substitute for peat in forestry nursery substrates [44]. The environmental response of the addition of sludge hydrochar in forest ecosystems can lead to a great reduction in GWP, TE, acidification, and eutrophication impacts compared to incineration and landfilling of sludge [20]. To date, the economic feasibility and social impact of using hydrochar as a fuel source or soil conditioner have not garnered as much attention as the environmental benefits. Only a few authors have investigated the economics of hydrochar for energy generation, mostly focusing on food waste as feedstock $[45,46]$, and in the case of hydrochar produced from pulp and paper mill sludge, no study has been conducted yet, to the knowledge of the authors of this paper.

Financial returns and social benefits contribute significantly in the promotion of renewable energy technologies $[47,48]$. Therefore, the authors would like to recommend an economic analysis in addition to the E-LCA before a more convincing selection can be made.

\section{Conclusions}

In this paper, the authors have studied the application of hydrochar pellets from pulp and paper mill sludges in CHP plants to substitute different fuel materials with the aim of identifying opportunities for improving its environmental performance. The results show that carbonization of the sludge feedstock, combined with pelletization to generate heat and power, can offer significant environmental benefits compared with incineration of the sludge. Between the scenarios, Scenario B, in which hydrochar substitutes coal, has significant environmental advantages (Human Health, Ecosystem Quality, and Climate Change damage categories) over Scenario A, where hydrochar substitutes solid waste. Scenario A was slightly better in terms of reduction in damage in the Resources endpoint category, due to the greater abatement in NRE and ME impacts. The results of the endpoint damage analysis prove that Scenario B delivers the highest environmental savings. This indicates the importance of heat and electricity generation from hydrochar pellets specifically when they are utilized to offset coal-based power sources. Decisions about using hydrochar-derived heat or electricity to replace the average Swedish energy mix (applied to other countries using coal-based energy sources) call for the investigation of specific environmental priorities. As a systems analysis study, some assumptions on emissions from HTC reactor and hydrochar combustion, energy recovery efficiency, and the fate of heavy metals were made in this assessment. Hence, to support decisions for implementation, it is recommended that future research works focus on reducing uncertainties, for instance by the use of site-specific emission and energy efficiency measurements, as well as methods to improve the fuel quality of the hydrochar pellets.

Author Contributions: Conceptualization, A.M.; methodology, A.M.; software, A.M.; formal analysis, A.M.; data curation, A.M.; writing—original draft preparation, A.M.; writing—review and editing, G.V. and S.E. and S.J. and K.G.; visualization, A.M.; supervision, K.G.; project administration, A.M., M.S. and K.G.; funding acquisition, A.M. and M.S. and K.G. All authors have read and agreed to the published version of the manuscript.

Funding: This research was funded by ÅForsk in Sweden with grant number "19-622".

Acknowledgments: The authors thank the reviewers who provided their expertise in evaluating and improving our manuscript, and also thank Kajsa Fougner for providing the required data on the HTC process.

Conflicts of Interest: The authors declare no conflict of interest. The funders had no role in the design of the study; in the collection, analyses, or interpretation of data; in the writing of the manuscript, or in the decision to publish the results. 


\section{References}

1. Mikhelkis, L.; Govindarajan, V. Techno-Economic and Partial Environmental Analysis of Carbon Capture and Storage (CCS) and Carbon Capture, Utilization, and Storage (CCU/S): Case Study from Proposed Waste-Fed District-Heating Incinerator in Sweden. Sustainability 2020, 12, 5922. [CrossRef]

2. Karlsson, J.; Brunzell, L.; Venkatesh, G. Material-flow analysis, energy analysis, and partial environmental-LCA of a district-heating combined heat and power plant in Sweden. Energy 2018, 144, 31-40. [CrossRef]

3. Brattebø, H.; Reenaas, M. Comparing $\mathrm{CO}_{2}$ and $\mathrm{NO}_{X}$ emissions from a district heating system with mass-burn waste incineration versus likely alternative solutions-City of Trondheim, 1986-2009. Resour. Conserv. Recycl. 2012, 60, 147-158. [CrossRef]

4. Persson, U.; Münster, M. Current and future prospects for heat recovery from waste in European district heating systems: A literature and data review. Energy 2016, 110, 116-128. [CrossRef]

5. SEA. Swedish Energy Agency. 2020. Available online: http://www.energimyndigheten.se/en/ (accessed on 1 May 2020).

6. Liu, Z.; Quek, A.; Balasubramanian, R. Preparation and characterization of fuel pellets from woody biomass, agro-residues and their corresponding hydrochars. Appl. Energy 2014, 113, 1315-1322. [CrossRef]

7. Reza, M.T.; Uddin, M.H.; Lynam, J.G.; Coronella, C.J. Engineered pellets from dry torrefied and HTC biochar blends. Biomass Bioenergy 2014, 63, 229-238. [CrossRef]

8. Islam, M.A.; Kabir, G.; Asif, M.; Hameed, B.H. Combustion kinetics of hydrochar produced from hydrothermal carbonisation of Karanj (Pongamia pinnata) fruit hulls via thermogravimetric analysis. Bioresour. Technol. 2015, 194, 14-20. [CrossRef]

9. Reza, M.T.; Lynam, J.G.; Vasquez, V.R.; Coronella, C.J. Pelletization of biochar from hydrothermally carbonized wood. Environ. Prog. Sustain. Energy 2012, 31, 225-234. [CrossRef]

10. Ahlroth, M.; Bialik, M.; Jensen, A. Hydrothermal carbonization of pulp- and paper mill effluent sludge. Bioresour. Technol. 2016, 200, 15-489.

11. Zhu, G.; Yang, L.; Gao, Y.; Xu, J.; Chen, H.; Zhu, Y.; Wang, Y.; Liao, C.; Lu, C.; Zhu, C. Characterization and pelletization of cotton stalk hydrochar from HTC and combustion kinetics of hydrochar pellets by TGA. Fuel 2019, 244, 479-491. [CrossRef]

12. International Organization for Standardization. ISO-14041. Environmental Management-Life Cycle Assessment-Goal and Scope Definition and Inventory Analysis; International Organization for Standardization: Geneva, Switzerland, 2006.

13. International Organization for Standardization. ISO-14043. Environmental Management-Life Cycle Assessment-Life Cycle Interpretation; International Organization for Standardization: Geneva, Switzerland, 2006.

14. International Organization for Standardization. ISO-14042. Environmental Management-Life Cycle Assessment-Life Cycle Impact Assessment; International Organization for Standardization: Geneva, Switzerland, 2006.

15. Khandelwal, H.; Dhar, H.; Thalla, A.K.; Kumar, S. Application of life cycle assessment in municipal solid waste management: A worldwide critical review. J. Clean. Prod. 2019, 209, 630-654. [CrossRef]

16. Mohammadi, A.; Khoshnevisan, B.; Venkatesh, G.; Eskandari, S. A Critical Review on Advancement and Challenges of Biochar Application in Paddy Fields: Environmental and Life Cycle Cost Analysis. Processes 2020, 8, 1275. [CrossRef]

17. Finnveden, G.; Johansson, J.; Lind, P.; Moberg, Å. Life cycle assessment of energy from solid waste-Part 1: General methodology and results. J. Clean. Prod. 2005, 13, 213-229. [CrossRef]

18. Berge, N.D.; Li, L.; Flora, J.R.V.; Ro, K.S. Assessing the environmental impact of energy production from hydrochar generated via hydrothermal carbonization of food wastes. Waste Manag. 2015, 43, $203-217$. [CrossRef]

19. Liu, X.; Hoekman, S.K.; Farthing, W.; Felix, L. TC2015: Life cycle analysis of co-formed coal fines and hydrochar produced in twin-screw extruder (TSE). Environ. Prog. Sustain. Energy 2017, 36, 668-676. [CrossRef] 
20. Mohammadi, A.; Sandberg, M.; Venkatesh, G.; Eskandari, S.; Dalgaard, T.; Joseph, S.; Granström, K. Environmental analysis of producing biochar and energy recovery from pulp and paper mill biosludge. J. Ind. Ecol. 2019, 23, 1039-1051. [CrossRef]

21. Mohammadi, A.; Cowie, A.L.; Anh Mai, T.L.; Brandão, M.; Anaya de la Rosa, R.; Kristiansen, P.; Joseph, S. Climate-change and health effects of using rice husk for biochar-compost: Comparing three pyrolysis systems. J. Clean. Prod. 2017, 162, 260-272. [CrossRef]

22. Mohammadi, A.; Govindarajan, V.; Sandberg, M.; Eskandari, S.; Granström, K. Life cycle assessment of combination of anaerobic digestion and pyrolysis: Focusing on different options for biogas use. Adv. Geosci. 2019, 49, 57-66. [CrossRef]

23. Swiss Centre for Life Cycle Inventories. Ecoinvent Database v.3.1. 2014. Available online: http://www. ecoinvent.org/ (accessed on 1 November 2019).

24. European-Commission. European Reference Life Cycle Database (ELCD Core Database); Version 3.2; Joint Research Centre (JRC) of the European Commission: Ispra, Italy, 2014. Available online: http://eplca.jrc.ec.europa.eu/ ELCD3/datasetDownload.xhtml (accessed on 1 November 2019).

25. Fuglesang, M.; Sivard, Å.; Törmälä, J.; Fougner, K. Biokol Från Bioslam-Pilotförsök; Report nr 2015:218; Energiforsk: Stockholm, Sweden, 2015; ISBN 978-91-7673-218-2. (In Swedish)

26. Parr Instrument Company. 2015. Available online: http://www.parrinst.com/ (accessed on 1 October 2019).

27. Yan, W.; Hastings, J.T.; Acharjee, T.C.; Coronella, C.J.; Vásquez, V.R. Mass and Energy Balances of Wet Torrefaction of Lignocellulosic Biomass. Energy Fuels 2010, 24, 4738-4742. [CrossRef]

28. Casanova-Peláez, P.J.; Cruz-Peragón, F.; Palomar-Carnicero, J.M.; Dorado, R.; López-García, R. RBF-ARX model of an industrial furnace for drying olive pomace. Energy Convers. Manag. 2012, 64, 106-112. [CrossRef]

29. Bartocci, P.; Bidini, G.; Saputo, P.; Fantozzi, F. Biochar pellet carbon footprint. Chem. Eng. 2016, 50, $217-222$.

30. Mohammadi, A.; Sandberg, M.; Venkatesh, G.; Eskandari, S.; Dalgaard, T.; Joseph, S.; Granström, K. Environmental performance of end-of-life handling alternatives for paper-and-pulp-mill sludge: Using digestate as a source of energy or for biochar production. Energy 2019, 182, 594-605. [CrossRef]

31. Benavente, V.; Fullana, A.; Berge, N.D. Life cycle analysis of hydrothermal carbonization of olive mill waste: Comparison with current management approaches. J. Clean. Prod. 2017, 142, 2637-2648. [CrossRef]

32. Larsen, H.F.; Hansen, P.A.; Boyer-Souchet, F. Deliverable 4.3 Decision Support Guideline Based on LCA and Cost/Efficiency Assessment; EU FP6 Project, Deliverable, No. 4.3; DTU Library: Lyngby, Denmark, 2010.

33. Li, L.; Diederick, R.; Flora, J.R.V.; Berge, N.D. Hydrothermal carbonization of food waste and associated packaging materials for energy source generation. Waste Manag. 2013, 33, 2478-2492. [CrossRef] [PubMed]

34. Reza, M.T.; Lynam, J.G.; Uddin, M.H.; Coronella, C.J. Hydrothermal carbonization: Fate of inorganics. Biomass Bioenergy 2013, 49, 86-94. [CrossRef]

35. Latosińska, J.; Gawdzik, J. The effect of incineration temperatures on mobility of heavy metals in sewage sludge ash. Environ. Prot. Eng. 2012, 38, 31-44. [CrossRef]

36. Lin, Y.; Ma, X.; Peng, X.; Hu, S.; Yu, Z.; Fang, S. Effect of hydrothermal carbonization temperature on combustion behavior of hydrochar fuel from paper sludge. Appl. Therm. Eng. 2015, 91, 574-582. [CrossRef]

37. PRè Consultants. SimaPro 8.0.4, Environmental Database; PRè Consultants: Amersfoort, The Netherlands, 2014.

38. Jolliet, O.; Margni, M.; Charles, R.; Humbert, S.; Payet, J.; Rebitzer, G.; Rosenbaum, R. IMPACT 2002+: A new life cycle impact assessment methodology. Int. J. Life Cycle Assess. 2003, 8, 324-330. [CrossRef]

39. Fang, J.; Zhan, L.; Ok, Y.S.; Gao, B. Minireview of potential applications of hydrochar derived from hydrothermal carbonization of biomass. J. Ind. Eng. Chem. 2018, 57, 15-21. [CrossRef]

40. Eriksson, O.; Finnveden, G.; Ekvall, T.; Björklund, A. Life cycle assessment of fuels for district heating: A comparison of waste incineration, biomass- and natural gas combustion. Energy Policy 2007, 35, 1346-1362. [CrossRef]

41. Owsianiak, M.; Ryberg, M.W.; Renz, M.; Hitzl, M.; Hauschild, M.Z. Environmental Performance of Hydrothermal Carbonization of Four Wet Biomass Waste Streams at Industry-Relevant Scales. ACS Sustain. Chem. Eng. 2016, 4, 6783-6791. [CrossRef]

42. Werner, S. District heating and cooling in Sweden. Energy 2017, 126, 419-429. [CrossRef]

43. Peters, J.F.; Iribarren, D.; Dufour, J. Biomass pyrolysis for biochar or energy applications? A life cycle assessment. Environ. Sci. Technol. 2015, 49, 5195-5202. [CrossRef] [PubMed] 
44. Eskandari, S.; Mohammadi, A.; Sandberg, M.; Eckstein, R.L.; Hedberg, K.; Granström, K. Hydrochar Amended Substrates for Production of Containerized Pine Tree Seedlings under Different Fertilization Regimes. Agronomy 2019, 9, 350.

45. Mazumder, S.; Saha, P.; McGaughy, K.; Saba, A.; Reza, M.T. Technoeconomic analysis of co-hydrothermal carbonization of coal waste and food waste. Biomass Convers. Biorefin. 2020. [CrossRef]

46. Mahmood, R.; Parshetti, G.K.; Balasubramanian, R. Energy, exergy and techno-economic analyses of hydrothermal oxidation of food waste to produce hydro-char and bio-oil. Energy 2016, 102, 187-198. [CrossRef]

47. Mohammadi, A.; Cowie, A.L.; Cacho, O.; Kristiansen, P.; Anh Mai, T.L.; Joseph, S. Biochar addition in rice farming systems: Economic and energy benefits. Energy 2017, 140, 415-425. [CrossRef]

48. Frondel, M.; Ritter, N.; Schmidt, C.M.; Vance, C. Economic impacts from the promotion of renewable energy technologies: The German experience. Energy Policy 2010, 38, 4048-4056. [CrossRef]

Publisher's Note: MDPI stays neutral with regard to jurisdictional claims in published maps and institutional affiliations.

(C) 2020 by the authors. Licensee MDPI, Basel, Switzerland. This article is an open access article distributed under the terms and conditions of the Creative Commons Attribution (CC BY) license (http://creativecommons.org/licenses/by/4.0/). 